\title{
Herbicide response polymorphism in wild populations of emmer wheat
}

\author{
J. W. SNAPE, E. NEVO,* B. B. PARKER, D. LECKIE \& A. MORGUNOV \\ Cambridge Laboratory, JI Centre for Plant Science Research, Colney Lane, Norwich NR4 9UJ, UK and *Institute of \\ Evolution, University of Haifa, Mt Carmel, Haifa 31999, Israel
}

\begin{abstract}
The responses of wild populations of emmer wheat (Triticum dicoccoides), from different ecogeographical areas of Israel, to three herbicides, difenzoquat, chlortoluron and metoxuron, commonly used on cultivated wheats, were studied. Although cultivated wheats are polymorphic for a response to difenzoquat, all families of all populations of the wild species were resistant. The species was, however, polymorphic for response to both chlortoluron and metoxuron. In addition, there appeared to be differentiation between populations in the frequencies of resistant and susceptible morphs for these herbicides. There was also a close correspondence between the responses of individual families to chlortoluron and metoxuron, which suggests a common genetic control. The implications of these findings for understanding the evolution of herbicide resistance, and for developing strategies for breeding for resistance in the cultivated species are discussed.
\end{abstract}

Keywords: emmer wheat, herbicides, polymorphisms.

\section{Introduction}

The use of effective and environmentally safe herbicides is an important component of maintaining high and stable agricultural production. Not infrequently, however, new varieties of crop species are susceptible to environmentally acceptable and/or widely used chemicals for which resistance would be desirable. Consequently there is, and will continue to be, a recurring need to introduce herbicide resistance genes into plant breeding programmes as new safer herbicides are developed and as weed spectra change.

For any particular crop species the available sources of genes for herbicide resistance will depend on the types of herbicides used for weed control and their mode of action. A crop series may indeed itself be polymorphic for responses, as, for example, wheat is for response to some phenylurea herbicides (Snape \& Parker, 1988). In this case, the introduction of resistance is straightforward by utilizing conventional methods for sexual hybridization in backcrossing programmes. If such variation does not exist within the species then alternative technologies must be employed. As a first step the responses of related, wild species can be examined. If resistance exists in these, then the techniques of interspecific hybridization and chromosome engineering can be used to introgress genes for resistance into the crop (see for example in wheat, Gale \& Miller, 1987). Finally, if no variation exists within related species then the techniques of genetic engineering must be used to introduce genes from wider biological sources including other plant species or bacteria (Oxtoby \& Hughes, 1989).

Wild emmer wheat (Triticum dicoccoides) is a tetraploid species which is a progenitor of both durum wheats, Triticum durum and bread wheats, Triticum aestivum. This species has been shown to be highly polymorphic for major gene variation and also highly variable for quantitative characters (Nevo et al., 1984; Nevo, 1987, 1988; Nevo \& Beiles, 1989). Much of this variation appears to have an adaptive significance for the species, and in addition, it can be an important source of genetic variation for improvement of the cultivated species. As the species is already demonstratively variable for a wide range of characteristics, it is of interest to examine whether it could be a source of variation for characters not yet examined, such as resistance to widely used herbicides to which the cultivated species are polymorphic or uniformly susceptible. The present experiments were initiated, therefore, to examine this possibility by studying the response of wild populations of emmer wheat from different ecogeographical areas of Israel to three widely used herbicides of cultivated wheat, difenzoquat, chlortoluron, and metoxuron, to which the 
cultivated wheats display herbicide response polymorphisms.

\section{Materials and methods}

\section{Populations studied}

Seventeen populations, taken as representatives of different ecogeographic regions of Israel, were chosen for study. These populations were a subset of a much larger study of genetic variation in $T$. dicoccoides of the Middle East region (Nevo \& Beiles, 1989). In the experiments each population was represented by a sample of families, where each family consisted of the progeny produced by the controlled self-pollination of individual plants collected in the wild. In all, 336 separate families were tested.

\section{Herbicides used}

Three herbicides commonly used for weed control in crops of cultivated bread and durum wheat were examined. First, two phenylurea herbicides, chlortoluron [3-(3-chloro- $p$-tolyl)-1, 1-dimethylurea] and metoxuron [3-(3-chloro-4-methoxyphenyl)-1, 1-dimethylurea]. These are widely used for the control of annual grass and broad-leaved weeds of wheat and barley. Variation in the tolerance of bread wheat varieties to chlortoluron and metoxuron has been reported (van Heile et al., 1970), and Snape \& Parker (1988) showed that the polymorphism for response to chloroluron is controlled by a single major gene locus on chromosome $6 \mathrm{~B}$. It is of interest, therefore, to examine whether the wild progenitor species is polymorphic or whether the polymorphism arose during cultivation.

Difenzoquat [1,2-dimethyl-3,5-diphenylpyrazolium] is used to control wild oat species in wheat, barley and rye. Again, differential responses are exhibited within bread wheat and have been shown to be controlled by variation at a major gene locus on chromosome $2 \mathrm{~B}$ (Snape et al., 1987). However, varieties of durum wheat appear to be almost uniformly susceptible to this herbicide and only one resistant variety has been found among a sample of world varieties (Leckie, 1989). It is of interest therefore to examine whether resistance exists in the wild progenitor species or evolved during cultivation of the bread wheats.

\section{Experimental techniques}

To test the responses to all three herbicides, individual plants for each population were grown either in the field under natural conditions or in a growth room under controlled conditions.

Field experiments were grown in 1986, 1987 and 1988. Each experiment consisted of a random block design where individual families were represented by microplot rows of five plants. The numbers of replicates of each family varied depending on the availability of seed, from 1 to 4 . Control plots of known resistant or susceptible varieties of bread wheat were randomized between the experimental families.

The experiments were sown either in the autumn or late winter and sprayed with the appropriate herbicide in late spring when the majority of plants had reached the 4-5 leaf stage, and when weather conditions were appropriate. Difenzoquat was sprayed at a dose rate of $2 \mathrm{~kg} \mathrm{ha}^{-1}$ active ingredient (a.i.), equivalent to twice the recommended dose. Chlortoluron and metoxuron were also sprayed at dose rates twice that recommended for farmers, namely $5.5 \mathrm{~kg}$ a.i. ha ${ }^{-1}$ and 8.25 $\mathrm{kg}$ a.i. ha ${ }^{-1}$, respectively. These doses were chosen on the results of previous experiments, which showed that they gave maximum differentiation between resistant and susceptible genotypes. Individual plants of each plot were scored for response 3-4 weeks after application.

Growth-room experiments were carried out under simulated day conditions of $16 \mathrm{~h}$ light at $20^{\circ} \mathrm{C}$ and $8 \mathrm{~h}$ dark at $15^{\circ} \mathrm{C}$. Initially, seed from each family was germinated in Petri dishes and then transplanted into $10-\mathrm{cm}$ pots containing John Innes Number 1 potting compost. Between 4 and 10 plants from each family were sown, together with appropriate controls. All pots were then individually randomized for each experiment in one large block. When the majority of plants had reached the 4-5 leaf stage they were removed from the growth room and sprayed with the appropriate herbicide at the same concentrations used for the field experiments. They were then replaced and rerandomized. Individual plants were scored for response 3 weeks after application.

In both environments, field and growth room, qualitative (resistant or susceptible) scores were taken, relative to the performance of the controls, as well as a quantitative score of damage, on a 1-9 scale. A score of 1 indicated no perceivable effect of the herbicide and a score of 9 severe damage or plant death. In most experiments it was possible to classify individual families unambiguously and qualitatively as being uniformly resistant, intermediate, or susceptible, or segregating relative to the bread wheat controls. Generally, resistant families correlated with quantitative scores of 1-3, intermediate as 4-7, and susceptible as $8-9$. 


\section{Results}

\section{Response to difenzoquat}

To test the responses to difenzoquat, a single experiment was grown in the field in 1986. This contained a sample of 157 families, representatives of 17 different populations, together with bread wheat control varieties of Chinese Spring (resistant to difenzoquat) and Sicco (susceptible to difenzoquat). All genotypes were replicated. Individual plants of each plot were scored for response 4 weeks after spraying.

Clear-cut, qualitative differences were observed between the responses of the control varieties, (Table 1), with Chinese Spring exhibiting a mean score of 2.1 and Sicco of 8.6. This differentiation was consistent over the experimental area for these varieties confirming the uniform application of the herbicide. Table 1 also shows the mean response and range of scores for each $T$. dicoccoides population. All plants of all families appeared to be resistant to difenzoquat.

Analysis of variance of these data failed to detect any differences between families within populations or between populations. Indeed no plant was recorded with a score greater than 2 and all families and popula- tions appeared homogenous for resistant genotypes. This result is surprising in view of the almost uniform susceptibility previously observed in tests of cultivated durum wheat varieties (Leckie, 1989). It appears, therefore, that this wild species may be monomorphic for the resistance allele at the locus for response to difenzoquat located on chromosome 2B (Snape et al., 1987). These results may imply that the allele for susceptibility to difenzoquat arose subsequently to the cultivation of tetraploid wheats and during the evolution or cultivation of bread wheats, that is during the last 9000-10,000 years (Zohary \& Hopf, 1988). Alternatively this could be a founder effect, although this is unlikely because the region is regarded as a centre of diversity for tetraploid wheats.

\section{Response to chlortoluron}

Two field experiments were carried out to examine the response of individual families from 11 populations. The first experiment from an autumn sowing in 1986 contained 113 families grown in four replications. The second, sown early in spring 1987 , contained a further 95 families which had not been tested in the first

Table 1 Response of wild populations of emmer wheat to application of the herbicide, difenzoquat (1-9 scale)

\begin{tabular}{lrlll}
\hline $\begin{array}{l}\text { Population* } \\
\text { Controls }\end{array}$ & $\begin{array}{l}\text { Number of } \\
\text { families tested }\end{array}$ & $\begin{array}{l}\text { Mean } \\
\text { response }\end{array}$ & Range & Classification \\
$\quad$ Chinese spring & 1 & & & \\
$\quad$ Sicco & 1 & 2.1 & $1-3$ & Resistant (R) \\
& & 8.6 & $7-9$ & Susceptible (S) \\
Ahihud & 8 & 1.0 & All 1 & All R \\
Amirim & 7 & 1.0 & All 1 & All R \\
Bat-Shelomo & 15 & 1.1 & $1-2$ & All R \\
Bet-Meir & 6 & 1.2 & $1-2$ & All R \\
Daliyya & 8 & 2.0 & All 2 & All R \\
Givat-Koach & 6 & 1.0 & All 1 & All R \\
Jaba & 7 & 1.0 & All 1 & All R \\
Kokhav-Hashahar & 13 & 1.2 & $1-2$ & All R \\
Mt Dov & 12 & 1.0 & All 1 & All R \\
Nesher & 11 & 1.1 & $1-2$ & All R \\
Qazrin & 13 & 1.0 & All 1 & All R \\
Rosh-Pinna & 10 & 1.3 & $1-2$ & All R \\
Sanhedriyya & 4 & 1.0 & All 1 & All R \\
Tabigha & 11 & 1.1 & $1-2$ & All R \\
Taiyiba & 6 & 1.0 & All 1 & All R \\
Yabad & 5 & 1.4 & $1-2$ & All R \\
Yehudiyya & 15 & 1.1 & $1-2$ & All R \\
\hline
\end{tabular}

*See Nevo \& Beiles (1989) for geographical and climatological data concerning population sites. 
Table 2 Responses of wild populations of Emmer wheat to application of $2 \times$ recommended dose of chlortoluron (1-9 scale)

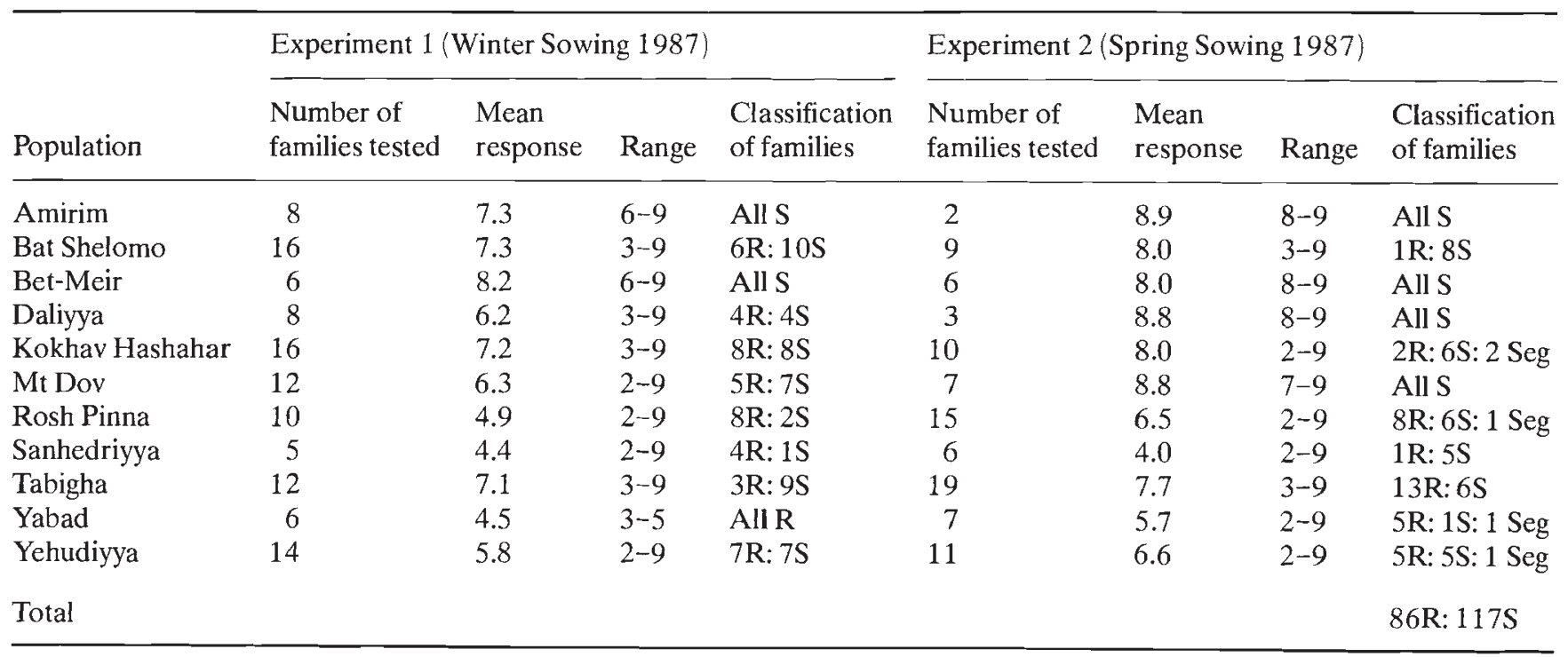

experiment, and was grown in two replications. Both experiments also contained plots of control varieties Cappelle-Desprez (resistant) and Chinese Spring (susceptible) dispersed systematically over the experimental area to test the adequacy of the spraying regime.

The numbers of families tested for each population, the mean population response, and the range of response between individual plants within each population, measured on a 1-9 scale, are shown in Table 2. The qualitative classifications of individual families of each population relative to the controls, which had the expected responses over the whole of the experimental area, are also shown in Table 2.

In both experiments it was apparent that there were genetic differences between families, which indicates that $T$. dicoccoides is polymorphic for response to chlortoluron. Individual families were generally homogeneous for response, with plants being either susceptible or resistant, although six families segregated. Nine populations examined were polymorphic and two populations, Amirim and Bet Meir, were monomorphic for susceptible individuals. Analyses of variance of the data for the two experiments separately are shown in Table 3 and confirm genetical differences between individual families within populations and between population means. Clearly $T$. dicoccoides, like bread wheat, is polymorphic for a response to chlortoluron and it is likely that this is determined by the locus on chromosome $6 \mathrm{~B}$ identified by Snape $\&$ Parker (1988). If this is the case, the susceptible allele appears to be at a slightly higher frequency than the resistance allele (117S morphs to $86 \mathrm{R}$ morphs), although there is no consistent pattern within populations. These vary from being monomorphic for susceptibility, to popula- tions, such as Yabad, being polymorphic although with a great excess of resistant genotypes.

\section{Response to metoxuron}

Two hundred and sixty-five families from 17 populations were examined for variation in response to metoxuron in a growth room experiment. Due to the shortage of space, each family was represented by only two individuals. Nevertheless, clear differentiation between families and individual plants was observed and both quantitative and qualitative scores of response were obtained. Table 4 shows the mean response of each population and a qualitative classification of families within each population.

Clearly, as with chlortoluron, there is a polymorphism for response with both inter- and intrapopulation variability. Analysis of variance of the raw data (Table 3 ) confirms that these differences are genetically based. All individual populations were polymorphic, and overall, as with chlortoluron, susceptible morphs were at a higher frequency $(176 \mathrm{~S}$ to $100 \mathrm{R})$ than resistant morphs.

\section{Relationship between responses to chlortoluron and metoxuron}

An examination of Tables 2 and 4 shows that there is a correspondence between the frequencies of families susceptible to both chlortoluron and metoxuron within individual populations. To investigate this further, both inter- and intrapopulation correlation coefficients were calculated between means scores of families common 
Table 3 Analyses of variance of differences within and between populations for response to chlortoluron, and metoxuron

\begin{tabular}{|c|c|c|c|c|c|c|}
\hline \multirow[b]{2}{*}{ Item } & \multicolumn{2}{|c|}{$\begin{array}{l}\text { Chlortoluron } \\
\text { experiment } 1\end{array}$} & \multicolumn{2}{|c|}{$\begin{array}{l}\text { Chlortoluron } \\
\text { experiment } 2\end{array}$} & \multicolumn{2}{|c|}{ Metoxuron } \\
\hline & d.f. & MS & d.f. & MS & d.f. & MS \\
\hline Between populations & 10 & $63.91^{* * *}$ & 10 & $29.70^{* * *}$ & 16 & $14.86^{* * *}$ \\
\hline $\begin{array}{l}\text { Between families within } \\
\text { populations }\end{array}$ & 104 & $12.84^{* * *}$ & 85 & $4.76^{* * *}$ & 249 & $3.66^{* * *}$ \\
\hline $\begin{array}{l}\text { Between plants within } \\
\text { families }\end{array}$ & 282 & 1.31 & 89 & 1.44 & 263 & 1.11 \\
\hline
\end{tabular}

Significance levels: ${ }^{* * *} P<0.01$. MS $=$ mean square.

Table 4 Responses of wild populations of emmer wheat to application of the herbicide, metoxuron (1-9 scale)

\begin{tabular}{|c|c|c|c|}
\hline Population & $\begin{array}{l}\text { Number of } \\
\text { families tested }\end{array}$ & $\begin{array}{l}\text { Mean } \\
\text { response }\end{array}$ & $\begin{array}{l}\text { Classification } \\
\text { of families }\end{array}$ \\
\hline Ahihud & 13 & 6.9 & 1R: $12 \mathrm{~S}$ \\
\hline Amirim & 10 & 6.2 & 2R: $8 \mathrm{~S}$ \\
\hline Bat-Shelomo & 24 & 6.6 & 6R: $18 \mathrm{~S}$ \\
\hline Bet Meir & 17 & 6.3 & 4R: 13S \\
\hline Daliyya & 16 & 5.8 & 4R: $12 \mathrm{~S}$ \\
\hline Givat Koach & 10 & 6.3 & $3 \mathrm{R}: 7 \mathrm{~S}$ \\
\hline Jaba & 20 & 5.4 & 12R: $8 \mathrm{~S}$ \\
\hline Jabad & 12 & 4.7 & 9R: 3S \\
\hline Kokhav Hashahar & 26 & 6.3 & 11R: $15 \mathrm{~S}$ \\
\hline Mt Dov & 17 & 6.4 & 4R: 13S \\
\hline Nesher & 5 & 6.4 & 1R: 4S \\
\hline Qazrin & 24 & 6.8 & 3R: $21 \mathrm{~S}$ \\
\hline Rosh Pinna & 20 & 5.4 & $10 \mathrm{R}: 10 \mathrm{~S}$ \\
\hline Sanhedriyya & 7 & 5.4 & 5R: $2 \mathrm{~S}$ \\
\hline Tabigha & 19 & 5.0 & 10R:9S \\
\hline Taiyiba & 11 & 6.0 & 3R: 8S \\
\hline Yehudiyya & 25 & 5.3 & 12R: $13 \mathrm{~S}$ \\
\hline Total & & & 100R: $176 \mathrm{~S}$ \\
\hline
\end{tabular}

to chlortoluron field experiments 1 and 2 and the metoxuron growth room experiment.

Seventeen populations were common to chlortoluron field experiment 1 and 11 to chlortoluron experiment 2 and the metoxuron experiment. Significant correlations of $0.71 \quad(P<0.001)$ and 0.74 $(P<0.001)$, respectively, were obtained between mean population scores for the two herbicides. Thus the population differentiation in the relative frequencies of susceptible and resistant families is common to both herbicides. In addition, 16 of these populations contained individual families common to chlortoluron experiment 1 and the metoxuron experiment so that intrapopulation correlation coefficients could be calculated. These are shown in Table 5 and reveal that
Table 5 Intrapopulation correlation coefficients between mean family scores for response to chlortoluron (experiment 1) and metoxuron

\begin{tabular}{lcc}
\hline Population & $\begin{array}{l}\text { Number of } \\
\text { common families }\end{array}$ & $\begin{array}{c}\text { Correlation } \\
\text { coefficient }\end{array}$ \\
\hline Ahihud & 8 & $0.91^{*}$ \\
Amirim & 8 & 0.66 \\
Bet Meir & 6 & 0.31 \\
Givat Koach & 5 & 0.84 \\
Jaba & 7 & 0.33 \\
Daliyya & 8 & -0.31 \\
Jabad & 6 & 0.55 \\
Qazrin & 16 & 0.24 \\
Yehudiyya & 15 & 0.34 \\
Rosh Pinna & 10 & $0.65^{*}$ \\
Sanhedriyya & 5 & -0.24 \\
Mt Dov & 13 & $0.79^{*}$ \\
Tabigha & 9 & $0.82^{*}$ \\
Bat-Shelomo & 16 & $0.74^{*}$ \\
Taiyiba & 9 & $0.66^{*}$ \\
Kokhav Hashahar & 14 & $0.61^{*}$ \\
\hline
\end{tabular}

${ }^{*} P=0.05-0.01$.

seven of the populations show significant positive correlations between responses of families to chlortoluron and metoxuron, seven show non-significant but positive correlations and only two show negative correlations, which are non-significant. These results suggest that response to both chemicals is under a common genetic control in most populations, although there may also be genes for independent response in certain populations.

\section{Discussion}

These results indicate that wild populations of emmer wheat contain genes for resistance to commonly used herbicides although it is highly likely that the popula- 
tions have never previously been exposed to the herbicides. This finding has implications for developing breeding strategies for herbicide resistance in the cultivated species and also for understanding the evolution of herbicide resistance in weed populations.

The resistant response of the species to difenzoquat was surprising in view of the fact that the cultivated tetraploids appear almost uniformly susceptible and the cultivated hexaploids are polymorphic. Presumably this resistance is due to the $D f q 1$ gene, previously identified on chromosome 2B (Snape et al., 1987). This suggests that the 'wild type' state is of resistance and that susceptibility has developed during cultivation. Thus either a mutated susceptible allele has been under selection because of some other agronomically desirable pleiotropic effect, or it has 'hitchhiked' its way through breeding programmes through linkage with other desirable alleles. Although there is no means to distinguish between these hypotheses from these data, other studies by Leckie (1989) indicate that in hexaploid wheat, $D f q 1$ is linked to genes for disease resistance and yield performance where the susceptible allele of $D f q 1$ is associated in repulsion phase with desirable alleles for the other traits, and thus the resistance allele with agronomically undesirable alleles. This would support a linkage hypothesis. If this is also true of the tetraploids, it should be possible to create a recombinant chromosome with desirable alleles in repulsion phase in all these species. In this respect, such a chromosome may already exist in $T$. dicoccoides and it may be possible to choose an accession with several desirable traits as a donor for difenzoquat resistance to the cultivated tetraploid wheats. This transfer can be achieved by conventional backcrossing and selection since sexual hybridization between the wild and cultivated tetraploids is easily obtained.

The polymorphism for response to chlortoluron and metoxuron is common to both wild and cultivated wheat species. In hexaploid wheat, cross resistance to chlortoluron and metoxuron has been shown to be a property of the Sul locus on chromosome 6B (Snape et al., 1990). As individual families of $T$. dicoccoides show similar cross resistance it is likely to be due to this same gene. If this is the case then the differentiation between populations in the frequencies of susceptible and resistant families is most likely due to differences in allele frequencies at this locus. Such differences could be at random and transient or could be due to differential effects of selection or to linkage with other loci under selection. Nevo \& Beiles (1989) have shown that population differences for allozyme loci are partly predictable by climatic and edaphic factors (Nevo, 1987). It will be interesting to examine whether this is also the case for this particular polymorphism.
If selection is shown to be the likely cause of population differentiation it must, of course, be due to a pleiotropic effect of the locus responsible for herbicide response because it is extremely unlikely that the natural populations have been exposed repeatedly to the herbicides. Studies of differences between the morphs for performance traits, in the absence of herbicide application may give an idea of these effects. In bread wheats, resistance to phenylurea herbicides has been shown to be due to a detoxification mechanism associated with the activity of cytochrome $\mathrm{P}_{450}$-mixed function oxidases. If this is also the case for $T$. dicoccoides, studies of resistant and susceptible morphs for this system could help elucidate the exact biochemical basis of the differences. Ultimately, this could lead to the molecular isolation of the resistance gene.

In the United Kingdom the emergence of populations of blackgrass (Alopecurus myosuroides), which show cross resistance to phenylurea herbicides, is causing severe problems for weed control in cereal crops. The presence of the polymorphism in $T$. dicoccoides may indicate that the resistance gene is widespread in natural populations of the Graminae. If this is the case, then resistant populations of annual grasses could arise by the selection of already existing resistant forms rather than being the products of new mutations, and the use of phenylurea herbicides for annual grass weed control may be severely impaired.

\section{Acknowledgements}

Professor E. Nevo would like to acknowledge the financial support of the Wolfson Foundation, the Israel Discount Chair of Evolutionary Biology, and the Ancell-Teicher Research Foundation for Genetics and Molecular Evolution, and the Humana Inc. Kentucky.

\section{References}

GALE, M. D. AND MILLER, T. E. 1987. The introduction of alien genetic variation into wheat. In: Lupton, F. G. H. (ed.) Wheat Breeding: Its Scientific Basis, Chapman and Hall, London, pp. 173-210.

LECKIE, E. D. 1989. PhD Thesis, University of Cambridge.

NEVO, E. 1987. Plant genetic resources: prediction by isozyme markers and ecology. In: Rattazi, M. C., Scandalios, J. G. and Whitt, G. S. (eds), Isozymes: Current Topics in Biological and Medical Research. Vol. 16: Agriculture, Physiology and Medicine, Alan R. Liss, New York, pp. 242-267.

NEVO, E. 1988. Genetic resources of wild emmer wheat revisited: genetic evolution, conservation and utilisation. In: Miller, T. E. and Koebner, R. M. D. (eds), Proceedings Seventh International Wheat Genetics Symposium, Institute of Plant Science Research, Cambridge, pp. 121-126. 
NEVO, E. AND BEILES, A. 1989. Genetic diversity of wild emmer wheat in Israel and Turkey. Theoret. Appl. Genet., 77, 421-455.

NEVO, E., BEILES, A., GUTTERMAN, Y., STORCH, N. AND KAPLAN, D. 1984. Genetic resources of wild cereals in Israel and vicinity. I. Phenotype variation within and between populations of wild wheat, Triticum dicoccoides. Euphytica, 33, 717-735.

oxTOBY, w. AND HUGHES, M. A. 1989. Breeding for herbicide resistance using molecular and cell techniques. Euphytica, 40, 173-180.

SNAPE, J. W., ANGUS, W. J., PARKER, B. B. AND LECKIE, D. 1987. The chromosomal locations in wheat of genes conferring differential responses to the wild oat herbicide, difenzoquat. J. Agric. Sci., Cambridge, 108, 543-548.

SNAPE, J. W. AND PARKER, B. B. 1988. Chemical response polymorphisms: an additional source of genetic markers in wheat. In: Miller, T. E. and Koebner, R. M. Ds (eds) Proceedings Seventh International Wheat Genetics Symposium Institute of Plant Science Research, Cambridge, pp. 651-656.

SNAPE, J. W., LECKIE, D., PARKER, B. B. AND NEVO, E. 1990. The genetical analysis of exploitation of differential responses to herbicides in crop species. Proceedings 11th Long Ashton Symposium (in press).

VAN HEILE, F. J. H., HOMMES, A. AND VERVELDE, E. J. 1970. Cultivar differences in herbicide tolerance and their exploitation. In: Proceedings of the 10th British Weed Control Conference, pp. 111-117.

ZOHARY, D. AND HOPF, U. 1988. Domestication of plants in the old world. The origin and spread of cultivated plants in west Asia, Europe and the Nile Valley. Clarendon Press, Oxford. 